\title{
Data poverty: a global evaluation for 2009 to 2013 \\ - implications for and sustainable development and disaster risk reduction
}

\author{
Mathias Leidig, Richard M. Teeuw* and Andrew D. Gibson \\ University of Portsmouth, School of Earth and Environmental Sciences, \\ Centre for Applied Geosciences, Burnaby Building, Burnaby Road, \\ Portsmouth, Hampshire, PO1 3QL, UK \\ *Corresponding Author Email: richard.teeuw@port.ac.uk
} \begin{abstract}
downloaded without restriction or cost.
Abstract

The article presents a time series (2009-2013) analysis for a new version of the "Digital Divide" concept that developed in the 1990s. Digital information technologies, such as the Internet, mobile phones and social media, provide vast amounts of data for decision-making and resource management. The Data Poverty Index (DPI) provides an open-source means of annually evaluating global access to data and information. The DPI can be used to monitor aspects of data and information availability at global and national levels, with potential application at local (district) levels. Access to data and information is a major factor in disaster risk reduction, increased resilience to disaster and improved adaptation to climate change. In that context, the DPI could be a useful tool for monitoring the Sustainable Development Goals of the Sendai Framework for Disaster Risk Reduction (2015-2030). The effects of severe data poverty, particularly limited access to geoinformatic data, free software and online training materials, are discussed in the context of sustainable development and disaster risk reduction. Unlike many other indices, the DPI is underpinned by datasets that are consistently provided annually for almost all the countries of the world and can be
\end{abstract}


30

1

Keywords: data poverty, global digital divide, time series, global monitoring, sustainable

31 development.

\section{Introduction}

33 The divide in Information and Communication Technology (ICT) provision, between 34 different countries or regions of the world, is referred to as the global digital divide (Norris, 35 2001). Development programs, international funding agencies and qualified decision making 36 (i.e., decision making that is based on facts, measurements and maps) require standardized 37 indicators to measure the impact of their programs and decisions (Desiere et al., 2015). Poor quality data affects even high-profile international development efforts, such as the Millennium Development Goals (MDGs), set by the United Nations (UN). However, according to a report by an independent UN advisory group published on November 6th 2014, the figures used to track progress are unsteady. The availability of data on 55 core indicators for 157 countries has never exceeded 70\% (The Economist, 2014). Tools and methods to monitor the progress in achieving the MDGs have been limited. This is an issue that needs to be addressed with the Sustainable Development Goals of the Sendai Framework for Disaster Risk Reduction (2015-2030): an improved index is required to enable reliable, effective monitoring (Griggs et al., 2013).

The year 2015 was important for global policy, due to three UN processes: (i) the search for a long term agreement on dealing with greenhouse gases, (ii) the finalization and adoption of the Sustainable Development Goals; and (iii) the development of a successor to the Hyogo Framework for Action as a global disaster risk reduction plan. There is a link for all of them with respect to sustainable development, poverty, vulnerability, and disasters (Kelman et al., 2015). Current and emerging socio-economic and social-ecological system dynamics require a new set of easy to apply monitoring tools (Griggs et al., 2013, Benson \& Craig, 2014). When assessing poverty, specifically data poverty, indicators ideally follow the SMART criteria: Specific, Measurable, Available cost-effectively, Relevant and Timely available (The 
European Evaluation Network for Rural Development, 2014).

In the past few decades Information and Communication Technology (ICT) has profoundly altered societies around the world, with people and information becoming ever more connected (Buys et al., 2009). The evolving trends in access and consumption of ICT provide a useful metric of global development. Access to mobile phone networks, the Internet and social media have more recently had significant influence, not just for general social interaction, but also in sustainable development and disaster management applications (Houston et al., 2015). The metrics derived from these elements could also provide a better understanding of global development and new insights into variations in the vulnerability of societies.

The term 'digital divide' first became widely known through a U.S. Department of Commerce report, "Falling through the Net: A Survey of the 'Have Nots' in Rural and Urban America" (National Telecommunications and Information Administration, 1995). Today the term 'data poverty' is often linked to economic growth (World Bank, 2006, Buys et al., 2009, ITU, 2012). 'Digital divide' is, in general, defined as the gap between those who have good access to computers, digital data and information via the Internet, and those who do not (Van Dijk, 2006). Huang \& Chen (2010) and Hilbert (2011) provide a fairly recent discussion about the various aspects of the global digital divide. Baban et al. $(2004,2008)$ used a similar term, 'information poverty', in the context of a lack of effective and reliable data and information, for hazard assessment and decision-making in low-income countries.

To compare differences between countries in access to digital data, Leidig and Teeuw (2015a) developed the Data Poverty Index (DPI). In this article we use the DPI to analyse access to data and information in a time series from 2009 to 2013. The DPI focuses on technological aspects, but also considers the provision of university education as a measure of the level of possible sophistication of information usage. We carry out time series analysis on the Data Poverty Index to examine the dynamic state of the digital divide. While there is a 
general trend with regard to the income classification of the World Bank, there are further

83 trends, sometimes conflicting, when considering individual nations or when analysing the 84 trends from regional perspectives.

\section{Methodology}

86 The approach used here to evaluate and monitor national-scale changes in data poverty is 87 based on the methodology of Leidig and Teeuw (2015a). However, that method had to be

88 simplified because some of the indicators, such as information about households with a PC, or 89 mobile phone network coverage, are not freely available for the entire period analysed (2009 90 2013). The input data for the time series of the Data Poverty Index proposed here is entirely 91 derived from freely available sources. The majority of the data sets used were obtained from 92 the World Bank (World Bank data-website, 2014), which provides data that are more up-to93 date than data from the United Nations (UN data-website, 2014). The Data Poverty Index has 94 five factors (Figure 1):

$95 \quad$ Internet speed: (i) download and (ii) upload - a reliable and fast Internet connection is 96 needed to download data; to share and/or upload data; to view or contribute to social media and Volunteered Geographic Information (VGI) initiatives, such as crowdsource mapping (Yin et al., 2012, Yates \& Paquette, 2011, Goodchild \& Glennon, 2010); the data was derived from the Net-Index website (http://www.netindex.com/) to ensure politically independent data.

- (iii) Internet users: - the percentage of individuals of a country using the Internet. This indicates the proportion of a national population familiar with the Internet and how many people who are likely to benefit from Internet-delivered resources.

- (iv) Mobile Phone Subscriptions (per 100 people): In some countries, particularly in Africa, mobile device usage is more widespread than Internet usage, which should be taken into account when developing social media and VGI applications or preparing training materials. Subscriptions may also provide a measure of the potential of a 
country to get early warnings and contribute to disaster response efforts, for instance following the Haiti earthquake (Yates \& Paquette, 2011).

○ (v) Education - derived from the tertiary education enrolment ratio (World Bank data) and the quotient of the number of universities in a country, relative to the population of that country. This variable indicates the level of 'computer literacy' and hence provides an indication of the understanding of geoinformatic data and technologies, such as GIS or GPS.

Factors such as the number of Internet Users and Mobile Phone Subscriptions have been used in indices before. For instance the UN World Risk index (2011-14), or the 2012 ITU report (ITU, 2012) on measuring the information society. The 2012 ITU report linked information technology variables to national gross domestic product (GDP), rather than to the possibility of a country accessing data for disaster preparedness or response. The ITU report (ITU, 2012) and the World Risk Index (World Bank, 2014) contain important variables, such as mobile phone network coverage, or the percentage of insurance coverage. However, neither were considered in the development of the DPI because those datasets are either not available publicly, not freely available, or do not exist for the study period (2009 - 2013). Additionally, the UN World Risk Index (Alliance Development Works, 2013) lacks normalisation for reliable comparisons. A basic statistical analysis of the relationship of the factors can be found in Leidig and Teeuw (2015a). 


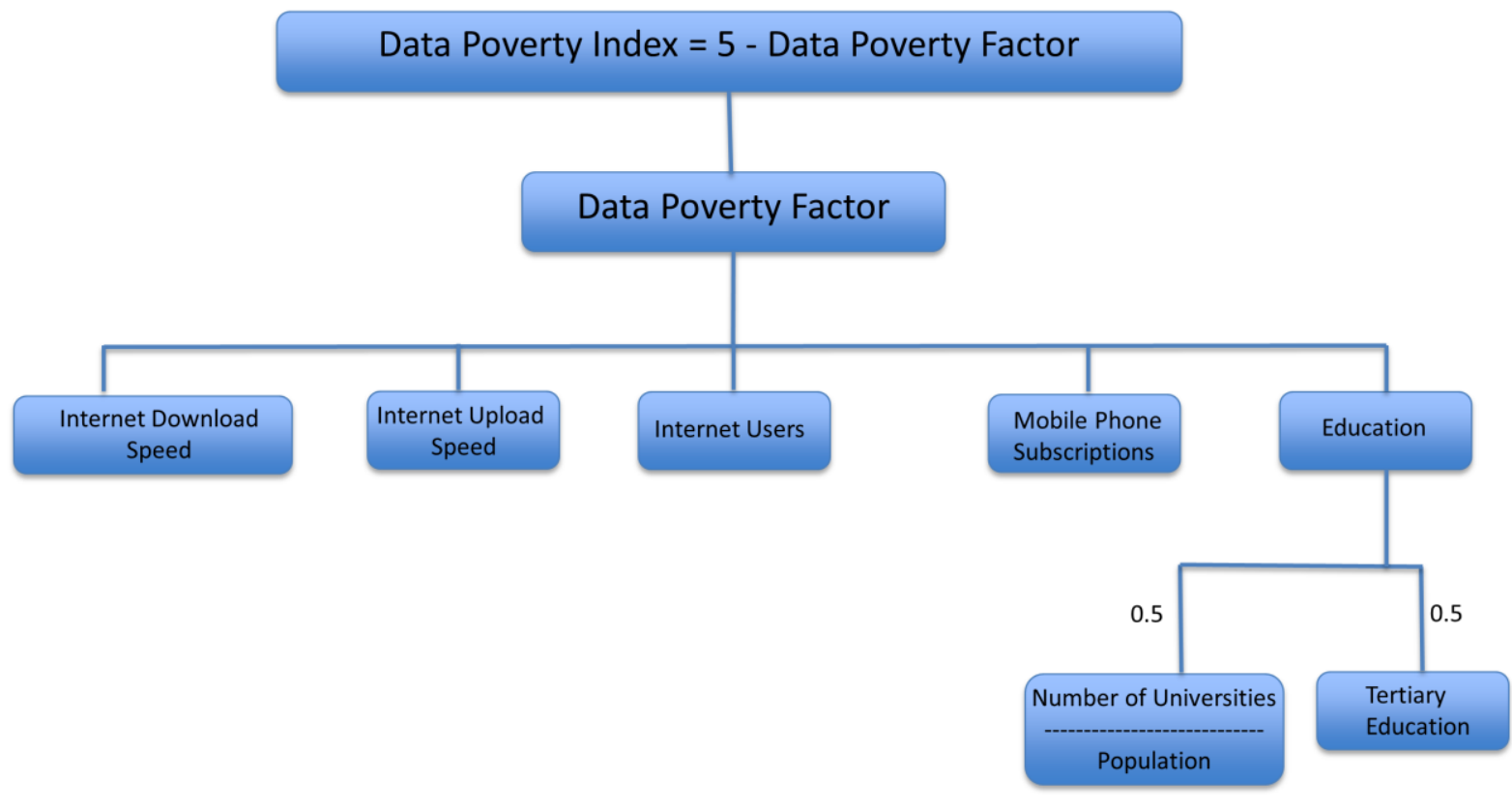

Figure 1: Data inputs used to calculate the Data Poverty Index.

For the calculation of the DPI time series, the input data was feature scaled (0-1) to provide a comparable representation of the individual variables. The calculated Data Poverty Factor was subtracted from the maximum score of 5 to obtain values for the Data Poverty Index: low values indicating minor data poverty, high values signifying severe data poverty.

Internet upload speed limits the dissemination of information and data, the use of social media and access to VGI initiatives. The maximum threshold for the Internet Speed/Upload category was set to $1 \mathrm{Mbps}$ : this is relatively low, but over the 5-year study period $1 \mathrm{Mbps}$ was progressively reached by the majority of countries. The $1 \mathrm{Mbps}$ threshold is equivalent to 7.5 $\mathrm{Mb}$ per minute, which would enable the upload of two to three 12 mega-pixel digital pictures per minute.

A download speed of at least $10 \mathrm{Mbps}$, which equates to downloading a DVD (4.7 GB) in 60 minutes, has been allocated the highest score in the Internet Speed/Download category, enabling an objective comparison between countries. The Internet speed score classes are based on the authors' experience with geoinformatic fieldwork, training and conferences in 143 many countries, from Europe to Africa, Asia and the Caribbean. That the thresholds for the 144 Internet speeds are reasonable, is illustrated by the equipment of a major UK Fire and Rescue 
Service (Hampshire: HFRS), which has a transmit and receive data rate of 492 Kbps. HFRS

also uses the 2G GPRS to 3G (HSPA) wireless broadband standard, with a possible 7.2 Mbps of $3 \mathrm{G}$, but that is rarely met during an emergency response: 2-3 Mbps is typical. Faster wireless broadband, such as $4 \mathrm{G}$, is currently not extensively used globally, due to insufficient coverage and high costs. Another major issue is slower speed in mobile networks because of concurrent usage, which is common in emergency response situations.

The percentage of mobile phone subscriptions was used as a measure of a country's mobile device usage. It was not possible to incorporate more variables, such as the percentage of network coverage, due to the absence of freely available data.

The information about university provision was obtained from the World Higher Education Database (World Higher Education Database, 2014) and gaps have been filled using the 4icu.org website (2014). The maximum number for the feature scaling was capped at 10 , which results in the top-scoring countries having at least one university per 100,000 people. This was necessary to remove extreme values for small countries that have one university for relatively few inhabitants (e.g. San Marino) and to ensure a reasonable representation when comparing countries and the other variables. Population and tertiary education data from the World Bank (World Bank data-website) were used; gaps were filled using United Nations data (UN data-website, 2014).

No further weighting or ranking among the factors for the Data Poverty Index was applied. This decision is based on expert discussion, which indicated that such a weighting introduces further subjectivity. For instance: The relative importance of a single variable might vary from metric application to application (e.g. sustainable development, disaster 167 vulnerability). Internet speed could be very important for disaster response, but when it comes to sustainable development or vulnerability reduction, education might play a more significant 169 role. 
The methodology provides data that are detailed enough to allow comparison and

differentiation among a wide range of countries, but it could also be modified for more detailed analysis, such as the DPI values of districts within a given country.

\section{Results}

For 122 countries, for which adequate datasets are available, we have analysed a complete multi-factor dataset to calculate the DPI time series from 2009 to 2013. For ease of comparison we use the World Bank income classification: high-income countries (HICs), upper-middle-income countries (UMICs), lower-middle-income countries (LMICs) and lowincome countries (LICs). The number of countries in each category with a complete dataset unfortunately differs: high-income countries are more likely to have a complete dataset. Of the 122 complete datasets there are: 10 LICs, 28 LMICs, 33 UMICs and 51 HICs. Hence, averages calculated for higher income countries are likely to be more reliable, having a lower standard deviation, than poorer countries. The extent to which countries in various regions and continents contribute a complete dataset for the data poverty time series analysis is indicated in Table 1.

\begin{tabular}{|c|c|c|c|}
\hline $\begin{array}{c}\text { Continent or } \\
\text { region in DPI } \\
\text { assessment } *^{1}\end{array}$ & $\begin{array}{c}\text { Number of countries on } \\
\text { continent } \\
\left.\text { (World Bank } *^{\mathbf{2}}\right)\end{array}$ & $\begin{array}{c}\text { Countries with } \\
\text { complete dataset for } \\
\text { DPI calculation }\end{array}$ & $\begin{array}{c}\text { Countries missing } \\
\text { data to calculate a } \\
\text { DPI }\end{array}$ \\
\hline Africa & 54 & $19(35 \%)$ & $35(65 \%)$ \\
\hline Asia*3 & 36 & $23(64 \%)$ & $13(36 \%)$ \\
\hline $\begin{array}{c}\text { Central America } \\
\text { \& Caribbean }\end{array}$ & 28 & $11(39 \%)$ & $17(61 \%)$ \\
\hline Europe & 47 & $42(89 \%)$ & $5(11 \%)$ \\
\hline Middle East* & 14 & $12(86 \%)$ & $2(14 \%)$ \\
\hline North America & 4 & $4(100 \%)$ & $0(0 \%)$ \\
\hline Oceania & 18 & $3(17 \%)$ & $15(83 \%)$ \\
\hline South America & 12 & $8(67 \%)$ & $4(33 \%)$ \\
\hline
\end{tabular}


$*^{1}$ The continent and regions classification used to present the DPI trends are based on the map references of the CIA World Factbook (https://www.cia.gov/library/publications/the-world-factbook).

$*^{2}$ The World Bank lists, e.g. for the Human Development Indicators (HDI), 214 countries and regions. The United Nations, e.g. the United Nations Statistics Division, lists 241 countries and regions. Since the majority of data used to calculate the DPI was obtained from the World Bank, the World Bank country list was used in this table. Greenland was not considered in the count for North America nor Europe.

$*^{3}$ Countries of the Middle East are listed with Asia in UN statistics (http://unstats.un.org/unsd/methods/m49/m49regin.htm) file and hence the above statistics uses the CIA World Factbook for the discrimination.

Table 1: Overview of the countries per continent providing a complete dataset to calculate the Data Poverty Index time series.

The missing data (Table 1) to calculate the DPI might, on its own, be an indication of data poverty. Many reports dealing with global development assessments, put Asia and Oceania into one category. In the classification used for this article, only three countries represent Oceania (Australia, New Zealand and Papua New Guinea). This might be misleading when looking at trends (e.g. Figure 5) because it indicates that for small island states in the Pacific region (and elsewhere, such as the Caribbean) there is inherently limited data availability for DPI analysis. However, there are few reasons not to merge the Asia and Oceania categories, not least because the countries of those regions often differ significantly in size and population. Countries or regions with missing data in Europa are often small islands (e.g. Faeroe Islands or Guernsey) or small territories and nations, such as Gibraltar and the Vatican.

The box-whisker plots in Figure 2 show that the DPI variation is generally decreasing: the average DPI score is moving closer to the global average of the corresponding year. The only exception among the HICs is Equatorial Guinea, which has a DPI score within the range of a low-income country. Of the low-income countries, a noteworthy negative outliner, as of 2013, is Burkina Faso: it has very low DPI scores in every category, particularly the education and Internet variables. On the other hand, the 2013 DPI score of Tajikistan is what we could expect in an upper-middle income country. 

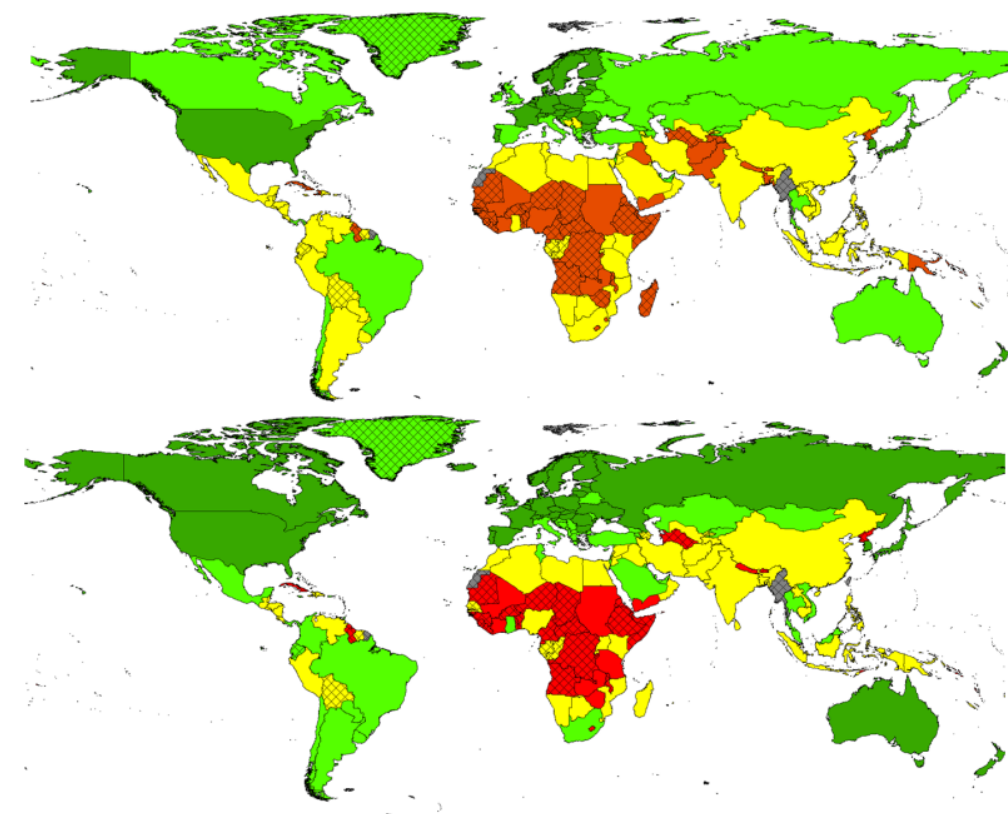

LICs UMICs UMICs HICs
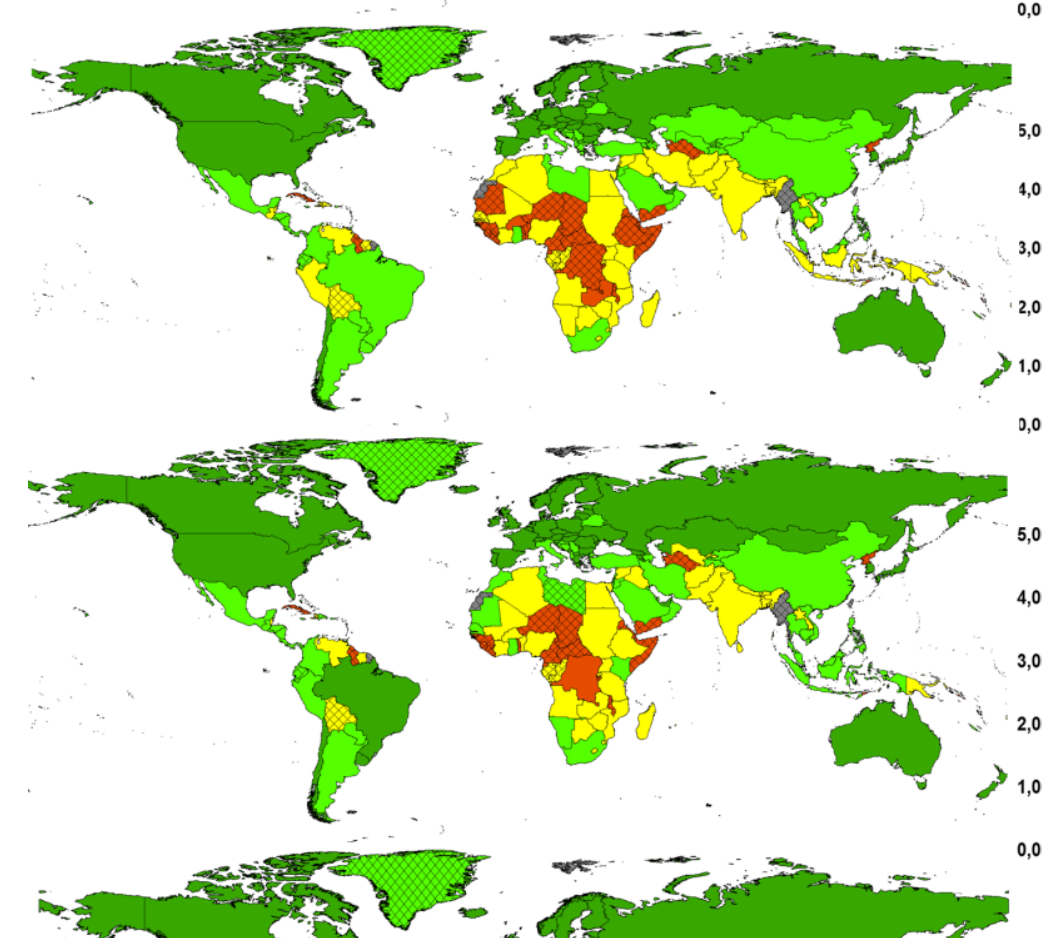

0,00

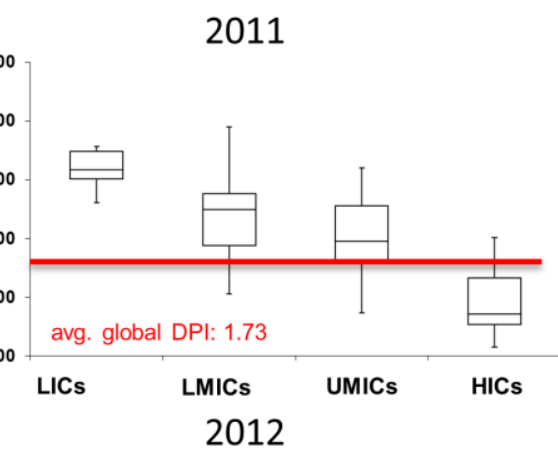

Legend
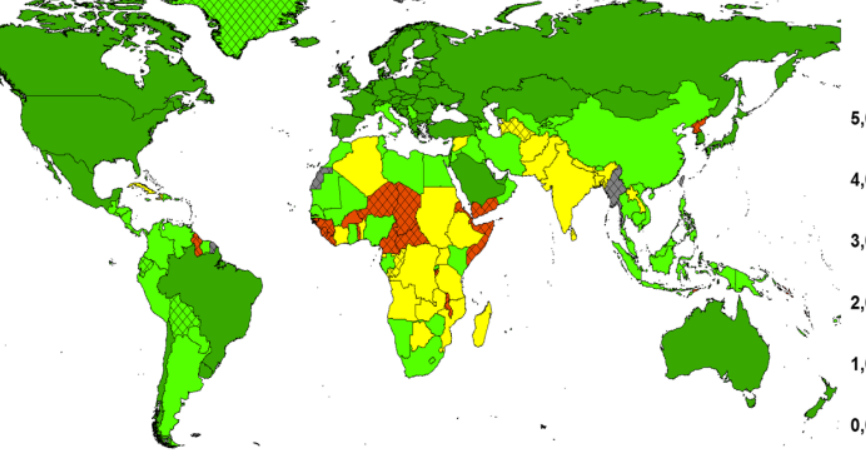

avg. global DPI: 2.01 LIC

LMICs

2011

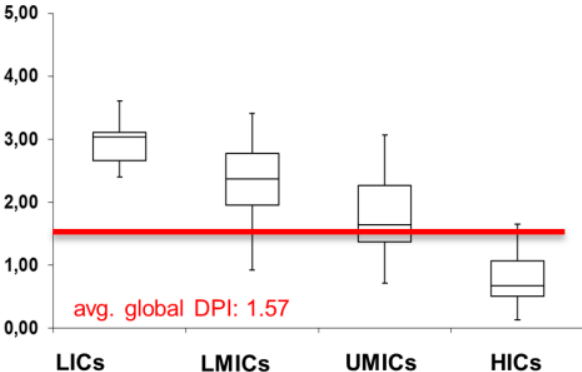

LICs UMICs UMICs HICs

2013

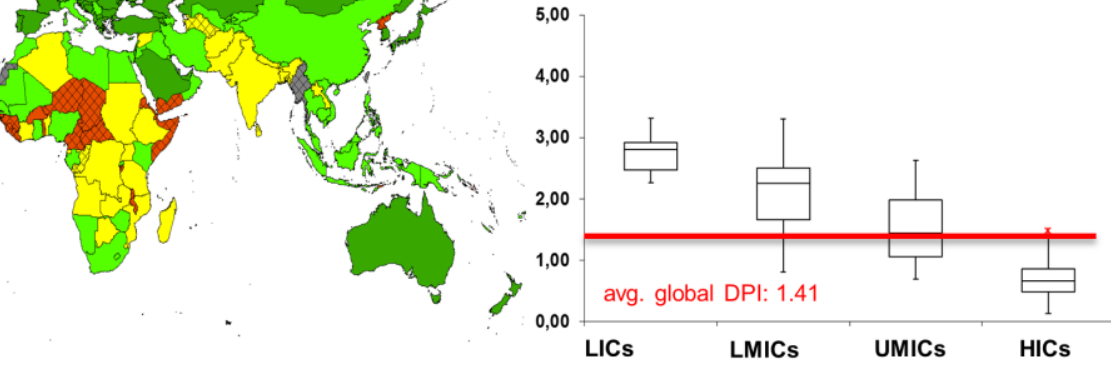

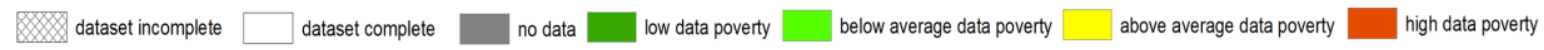

Figure 2: Data Poverty Index developments and changes from 2009 to 2013. For each year the corresponding Box-Whisker-Plot is represented, using the World Bank income classification and the average global DPI. 
210 Figure 2 and Figure 3 indicate that the average data poverty appears to be ever-decreasing in

1

each of the income categories. However, when the DPI values are normalised, by the difference to the average global DPI of the corresponding year, data poverty is revealed as steadily increasing in low-income countries. For LMICs the data poverty is also steadily increasing, though at a lower rate (Figure 4). The DPI trends observed for UMICs and HICs are decreasing, i.e. moving towards reduced data poverty, with HICs approaching a potential steady state condition - under the currently selected thresholds. The complexity is further emphasised when we examine the DPI results by looking at geographical regions rather than the World Bank income classification (Figure 4).

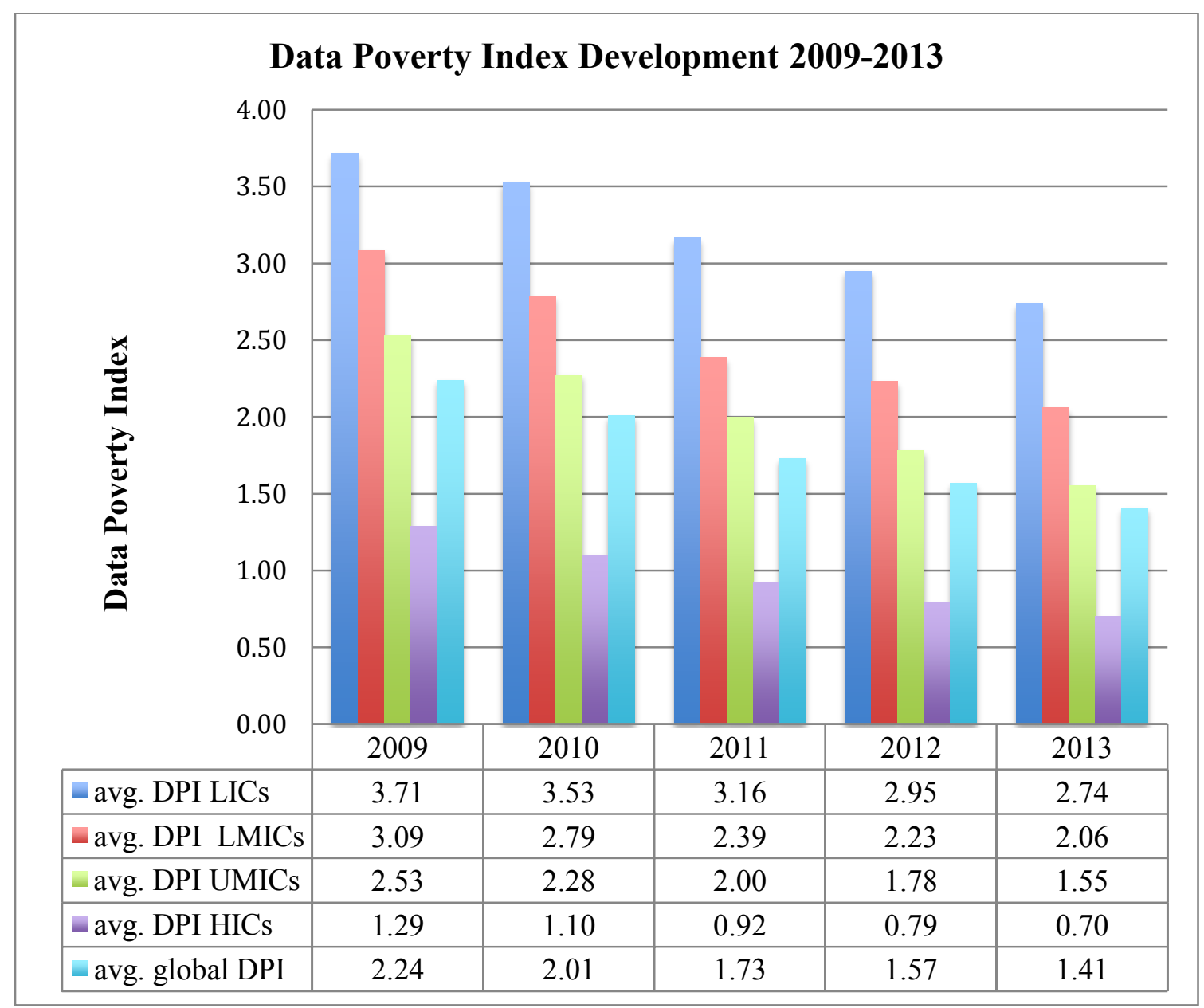

Figure 3: Data Poverty Index development between 2009 to 2013 for countries with a complete dataset for the time series.

222 The identified trends are non-linear: the fit with a polynomial trend line ( $3^{\text {rd }}$ order polynomial) can be seen in Figure 4. The average DPI has improved globally, reducing from 2.24 in 2009, 
224 to 1.41 in 2013. South America, Middle America and large parts of East Asia made

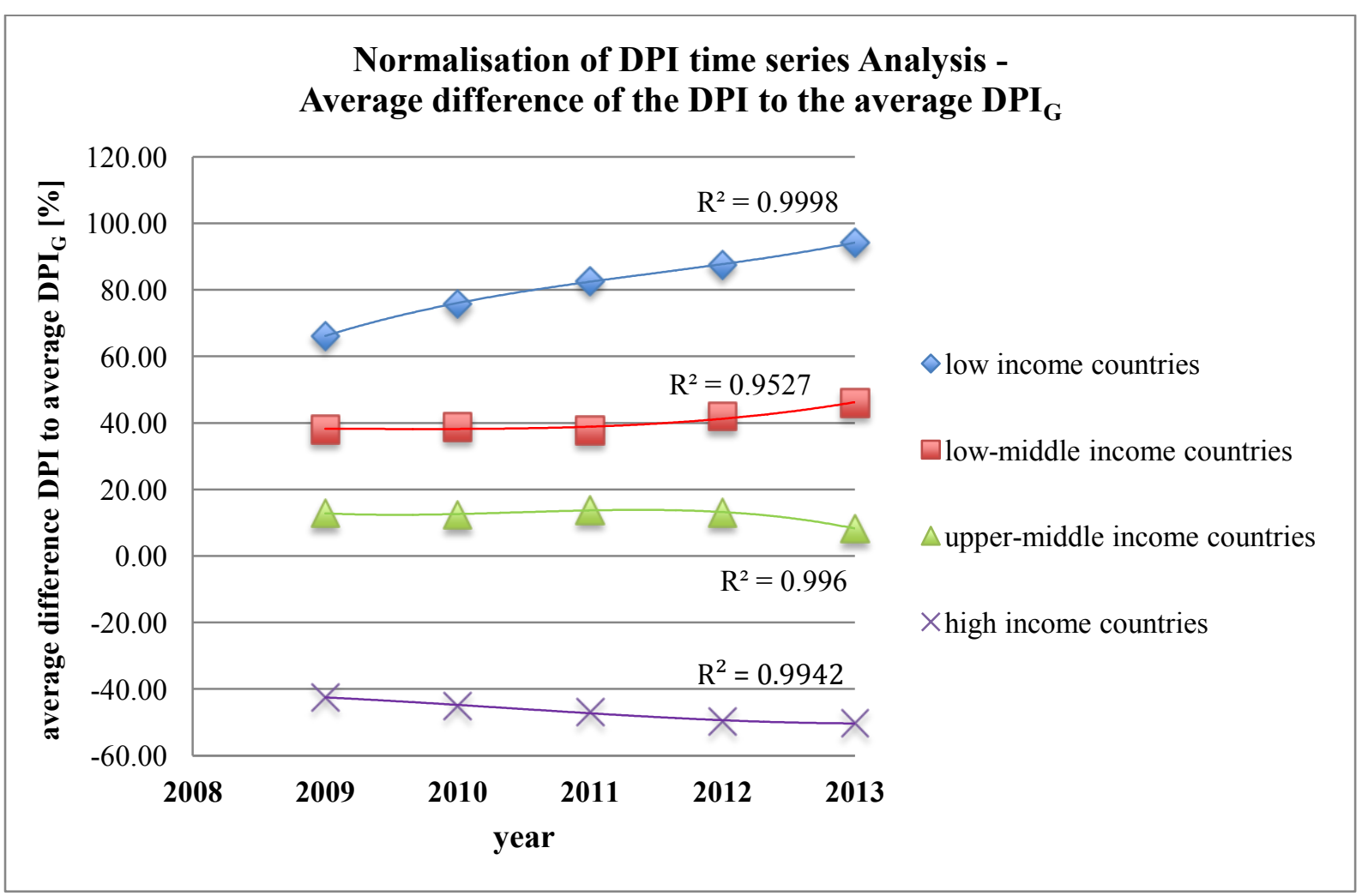

Figure 4: Normalization of DPI time series Analysis. Presented is the average difference of the DPI to the average global DPI $\left(D P I_{G}\right)$ for the corresponding year with a $3^{\text {rd }}$ order polynomial fit. The zero line represents the average of the global DPI for the corresponding year.

When separating the DPI results into geographical regions, the data poverty trends become even more diverse. Europe, North America and Oceania have the lowest data poverty, with Europe and North America approaching steady-state conditions, under the currently selected thresholds. The DPI variations in Oceania are higher, but still well below the global average. The Middle East, South America and Asia are above the global average for data poverty. The biggest reductions in data poverty, during the past five years, were in the Middle East. South America had slow reductions after big improvements from 2009 to 2010; while the trend in Asia is characterised by up and downs. Africa has significantly higher data poverty than the rest of the world and also hosts the most countries with incomplete or unreliable data. After a 
240 period of minimal change between 2010 and 2012, the 2013 average DPI value for Africa

1

2241 increased markedly (Figure 5, Table 2).

6

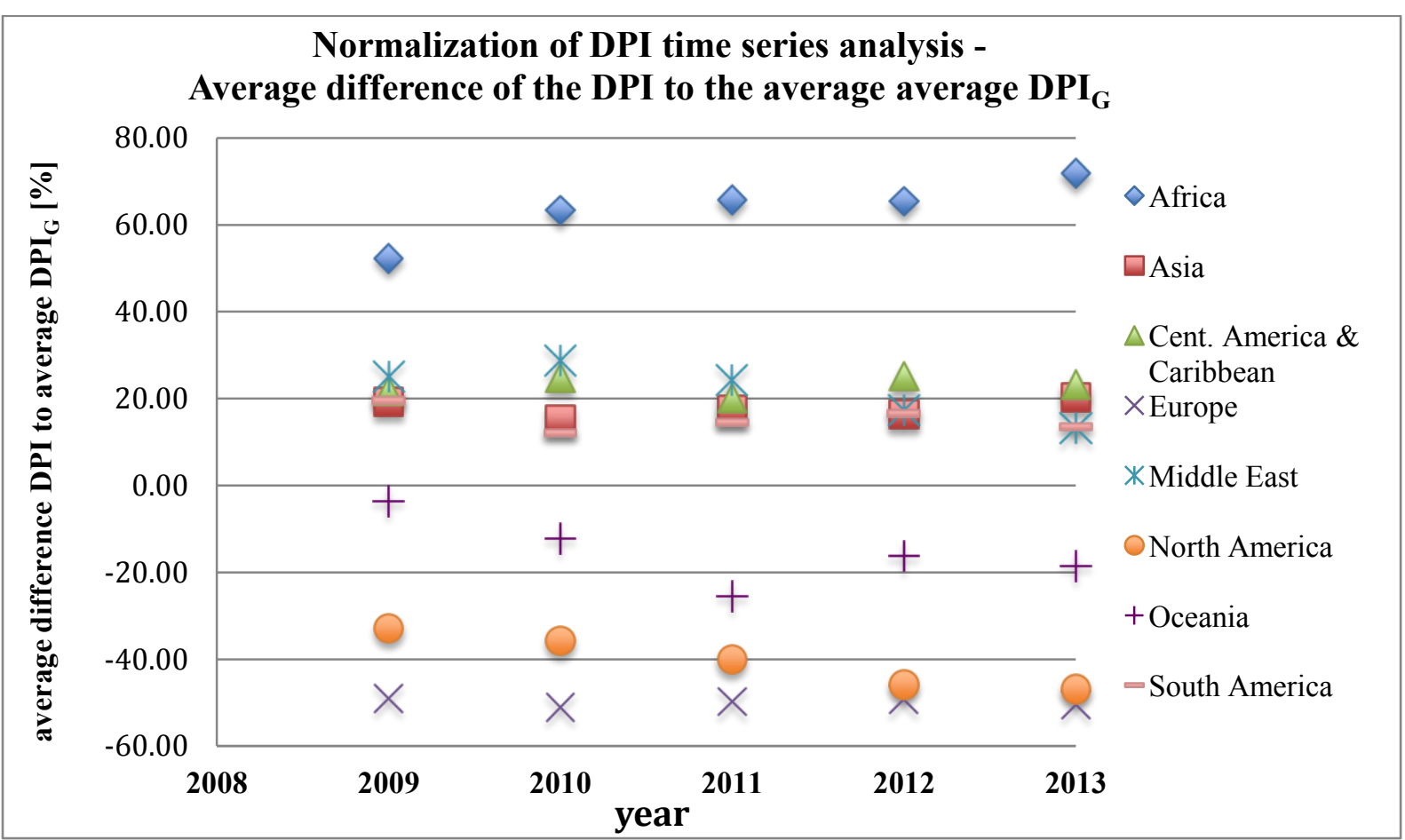

Figure 5: Normalization and trends of the data poverty index time series. While Figure 4 indicates the general trend when classifying the results according to the World Bank income classification, Figure 5 shows the trends when looking at the result from a continental or regional perspective.

\begin{tabular}{|c|c|c|c|c|c|c|}
\hline \multirow{2}{*}{$\begin{array}{c}\text { Continent/ } \\
\text { region }\end{array}$} & \multirow{2}{*}{$\mathbf{R}^{2 *}$} & \multicolumn{5}{|c|}{ average difference of DPI to the average global DPI [\%] } \\
\hline & & 2009 & 2010 & 2011 & 2012 & 2013 \\
\hline Africa & 0.99940 & 52.20 & 63.35 & 65.67 & 65.44 & 71.84 \\
\hline Asia & 0.73512 & 19.26 & 15.12 & 17.40 & 16.33 & 20.31 \\
\hline $\begin{array}{c}\text { Central } \\
\text { America \& } \\
\text { Caribbean }\end{array}$ & 0.07497 & 21.66 & 24.70 & 19.99 & 25.12 & 23.26 \\
\hline Europe & 0.93488 & -49.07 & -50.99 & -49.72 & -49.33 & -50.47 \\
\hline Middle East & 0.99996 & 24.93 & 28.78 & 24.21 & 17.23 & 13.20 \\
\hline $\begin{array}{c}\text { North } \\
\text { America } \\
\end{array}$ & 0.99414 & -32.89 & -35.80 & -40.05 & -45.87 & -46.90 \\
\hline Oceania & 0.79462 & -3.66 & -12.24 & -25.54 & -16.31 & -18.58 \\
\hline $\begin{array}{c}\text { South } \\
\text { America }\end{array}$ & 0.99004 & 19.47 & 12.13 & 14.50 & 16.65 & 13.47 \\
\hline
\end{tabular}

Table 2: The values underlying Figure 5 and $R 2$ for a $3^{\text {rd }}$ order polynomial trend.

249 Almost all HICs have reached a high level of technological development, but improvements are now predominantly possible by the incorporation of new technologies, such as new or 
updated hardware, new mobile phone network standards (e.g. from GPSR to LTE) or

improved Internet protocols.

The most prominent individual factors of the DPI are the Internet speeds, along with the number of Internet Users. In the 5-year period analysed, the educational variable contributes least to the overall DPI score. However, it is education that differs most when comparing high-income to low-income countries. The effects of education on the uptake of information and communication technology are discussed by van Dijk (2006).

A summary of the global Data Poverty Index change between 2009 and 2013 is presented in Figure 6. Countries that already had a low DPI in 2009, tend to have improved less, relative to countries with a higher DPI score. To analyse developments in Africa is challenging because for 35 countries in Africa there is no complete dataset for at least one of the years considered in the analysis (Table 1).

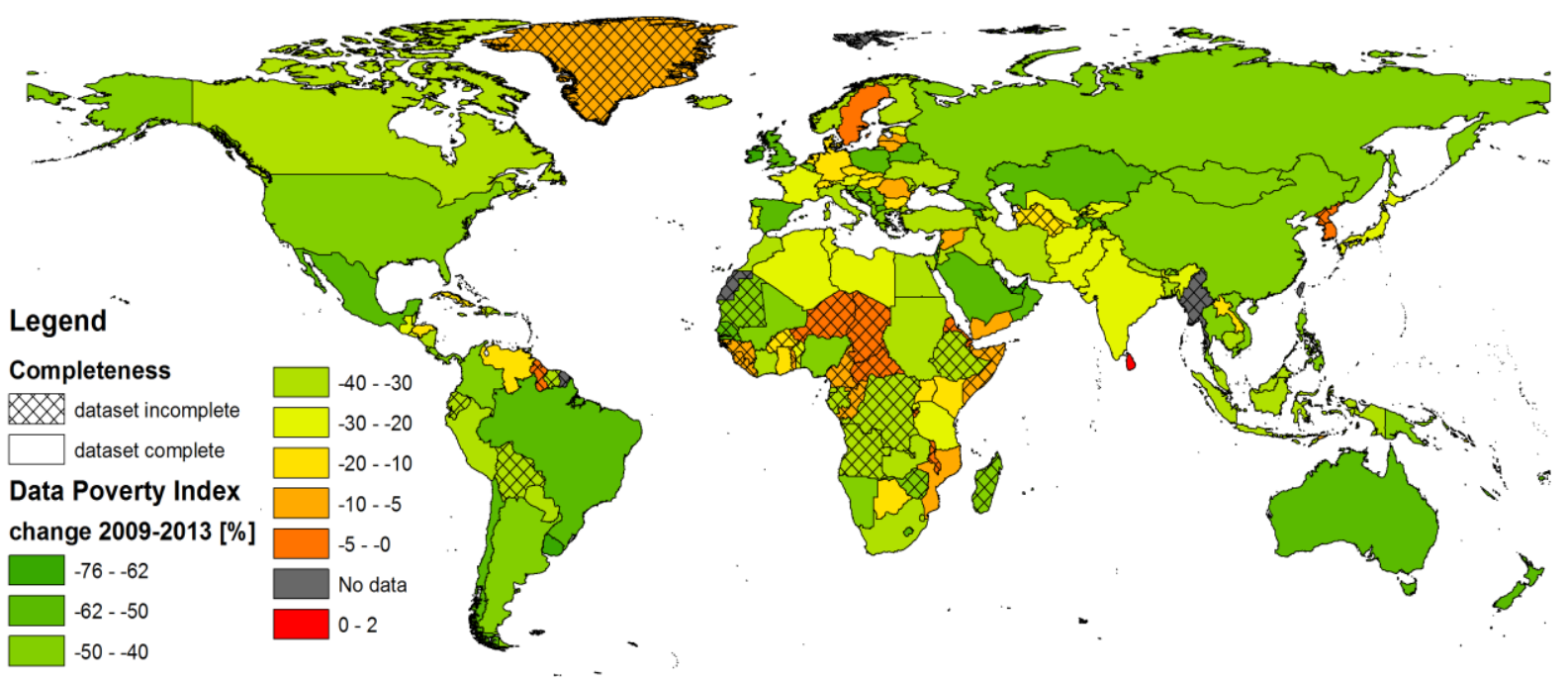

Figure 6: Relative Data Poverty change between 2009 and 2013.

\section{Discussion}

Previous studies dealing with the 'digital divide' contain few attempts to quantify and moreover visualise data poverty, or they did not look on the global scale and instead focused on one continent - often Africa (Ford, 2007, Fuchs \& Horak, 2008). The challenge for 
promoting and practicing sustainable development, and to improve disaster resilience, is to

recognise which developments are favourable (Barban et al., 2008).

The DPI time series indicates the potential of annual monitoring to identify shortcomings in information technology and communication infrastructure. Unfortunately, there is insufficient reliable and complete data before 2009 to extend the time series and check for longer-term trends. The quasi steady-state conditions reached by many HICs are likely to remain for some years because improvements in rural areas are slow to implement, for instance, with education or improved Internet access. Improvements in existing technology and Internet protocols (such as the recent introduction of http/2) may enhance the scores from HICs, but they are levelled by the thresholds that we introduced to make the DPI scores comparable among the different nations and income classes.

The decreasing average DPI in Asia from 2012 to 2013 might be due to the relatively large number of disasters that hit Asia during that period. According to the Centre for Research on the Epidemiology of Disasters (CRED), countries in Asia reported 83 disasters in 2012, mostly floods. Those disasters resulted in ca. 3,100 fatalities, affected 64.5 million people and caused about US\$15 billion in damage. China led the list of disaster frequency in 2012 (18), followed by Philippines (16), Indonesia (10), Afghanistan (9) and India (5) (Inrin News, 2015). These disasters adversely affected national infrastructure and industries, so it may well be that ICT features were also impacted, which is reflected in the DPI scores.

\section{Why is the DPI score of Africa so much worse than the other continents?}

There are many possible factors, but it is notable that many African countries often focus their economic development focuses on the exploitation of natural resources, rather than investment in ICT and higher education. Africa also has relatively few submarine Internet cables, severely limiting its capacity to link with the global Internet (PriMetrica Inc. - Tele Geography, 2014). Some of the countries with the highest projected population growth rates 
are in Africa (UN data-website, 2014), resulting in an increasing number of potential users

being in competition for limited ICT capabilities.

A 'digital global community' is nevertheless developing. The primary reason is the high availability of mobile phones and the corresponding increasing mobile network coverage, along with the high usage of mobile phones, even in developing countries (Buys et al., 2009). Van Dijk (2006) found that cultural, psychological and socio-economic aspects, such as how to finance fees for ICT and related hardware, are a hindrance in the development of digital communities. However, such hindrances are secondary, not least where mobile networks or Internet connections are not available in the first place.

Given the increasing number of mobile devices (e.g. phones, tablets and laptops), some studies concluded that the digital divide among individuals has increasingly been closing as the result of an almost automatic process (Compaine, 2001, Dutton et al., 2004). That argument is further emphasised by the percentage of households with a computer: in 2004, $0.6 \%$ of households in India and about $60 \%$ of households in the USA had a personal computer (Chinn \& Fairlie, 2004). In $201312 \%$ of households in India and $80 \%$ of households in the USA had a personal computer. This is still a significant gap but indicates the improvement on the example of a lower-middle income country (UN data-website, 2014).

Regarding the availability, access and consequent usage of digital networks, the limitations are generally greater for the Internet than for mobile phones. However, the numbers for mobile phone users, might be over-estimates, due to the habit of sharing mobile phones in the developing world - though recent fieldwork indicates that even in developing countries the trend is towards at least one mobile phone per person (James, 2011).

Another important issue concerns ICT skills and computer-literacy. Research shows that the digital divide is more than just an access issue and cannot be alleviated merely by providing the necessary equipment. Three main factors are involved: information accessibility, utilization and receptiveness. People need to know how to make use of 
information and communication tools once they exist within a community (Kim \& Kim,

2001). In the DPI calculation this is represented by the educational factor. Compared to the World Risk Report of the United Nations (UN University, 2014), we consider tertiary education because universities are the institutions where a lot of research and training for disaster preparedness is performed.

The global digital divide describes global disparities, predominantly between developed and developing countries, with regards to access to computing and information resources, such as the Internet and the opportunities derived from such access (Lu, 2001). The presented DPI methodology could be downscaled, for instance to examine differences between cities versus rural areas; or coastal plains versus mountainous regions. If the relevant input data does not exist, it could be easily collected, for instance by using VGI (Wesolowski et al., 2014, Davidson, 2014, Lüge et al., 2014, Pakhare et al., 2013).

The amount of information and data freely available from the Internet is expanding very quickly (Leidig \& Teeuw, 2015b, Teeuw et.al, 2012). However, not all countries are able to keep up with the frequent technological changes - particularly developing countries. The term 'digital divide' does not necessarily mean that someone does not have ICT technology; it could also mean that there are differences ICT availability, such as the provision of highquality computers, fast Internet, mobile network coverage, or limited technical assistance.

The trend towards a local minimum in Europe and North America indicates that these regions have reached a relatively good level of ICT coverage. Improvements those regions are, in short term, mainly possible by improved technology or by further developing rural and remote areas, which might take longer than the considered time series. Since we are in a dynamic system, a 'perfect' DPI score of 0 might not be possible. This is further analysed on the basis of the variables contributing to the DPI. The contribution of each factor to the DPI for the corresponding year is presented in Figure 7. Although there have been positive ICT developments in the study period, there is still a discrepancy i.e. in download speed between 
347 HICs and LICs - despite the fairly low and reasonable thresholds set. That discrepancy can

have major impacts on disaster risk reduction because fast download speeds are needed for effective early warning and for the supply of satellite imagery to guide disaster response. Moreover, to be able to download and process data is one of the major requirements for the application of the International Charter on Space and Major disasters (Danzeglocke, 2015).

Another major dividing factor is education; which is where HICs and LICs differ most. The education factor scores have not changed significantly but have been slightly altered by population growth. The difference among HICs and LICs is by a factor of six (average HICs $\sim 0.6$ and average LICs $\sim 0.1$ ). While the number of universities has not changed, based on the available data, it might be possible that universities have grown with respect to the population growth. Here further research and new metrics are needed to analyse such developments. Even an increase in tertiary education might not be an indication for progress but could also indicate congested universities.

The contribution of the download speeds in LMICs and UMICs is almost identical and showed significant progress compared to LICs in the considered time series with UMICs disengaging from the LMICs from 2012 to 2013. With regard to the contribution of mobile phone subscriptions, HICs and UMICs are almost on a par, and LMICs are catching up; however, it is encouraging that the contribution of this factor for LICs has increased by $100 \%$ (from 0.34 in 2009, to 0.68 in 2013). In summary, the technology-based aspects in the DPI (download speed, upload speed and mobile phone subscriptions) currently have a stronger contribution to the DPI score, but education and the number of Internet users are also significant factors. 


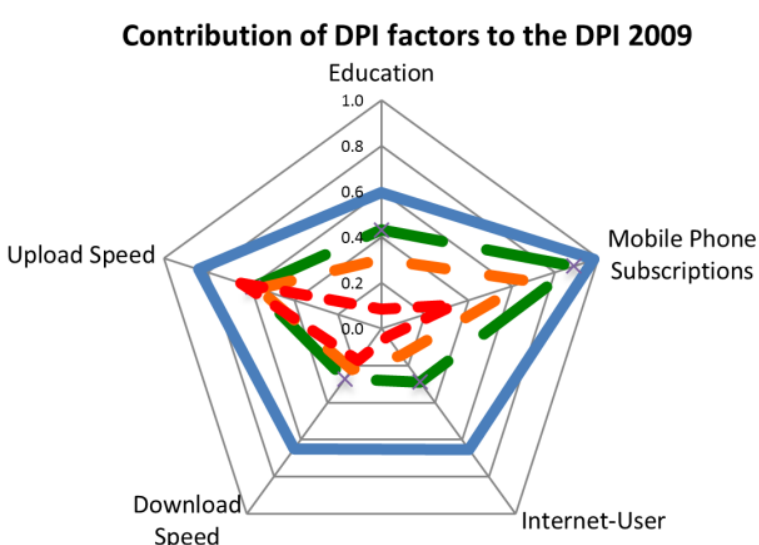

Contribution of DPI factors to the DPI 2011

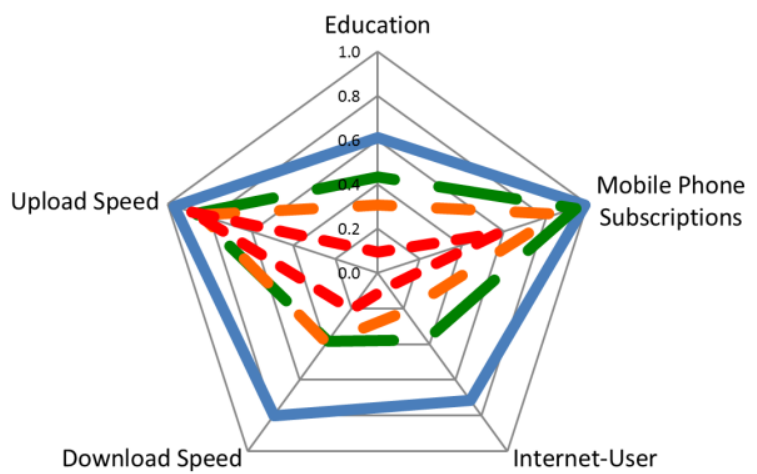

Contribution of DPI factors to the DPI 2013

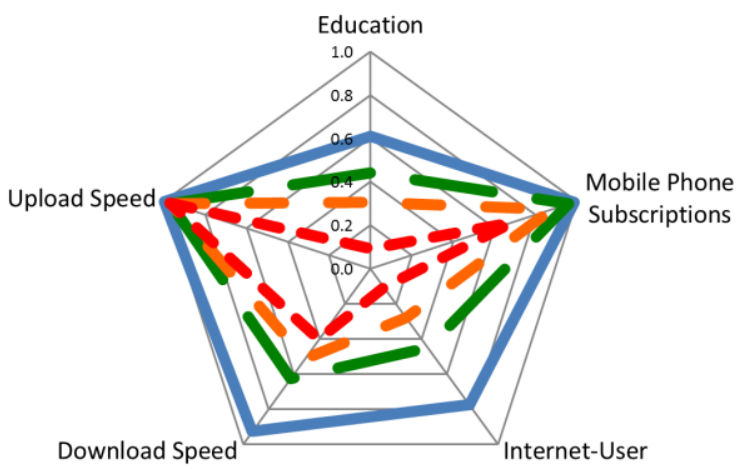

Contribution of DPI factors to the DPI 2010
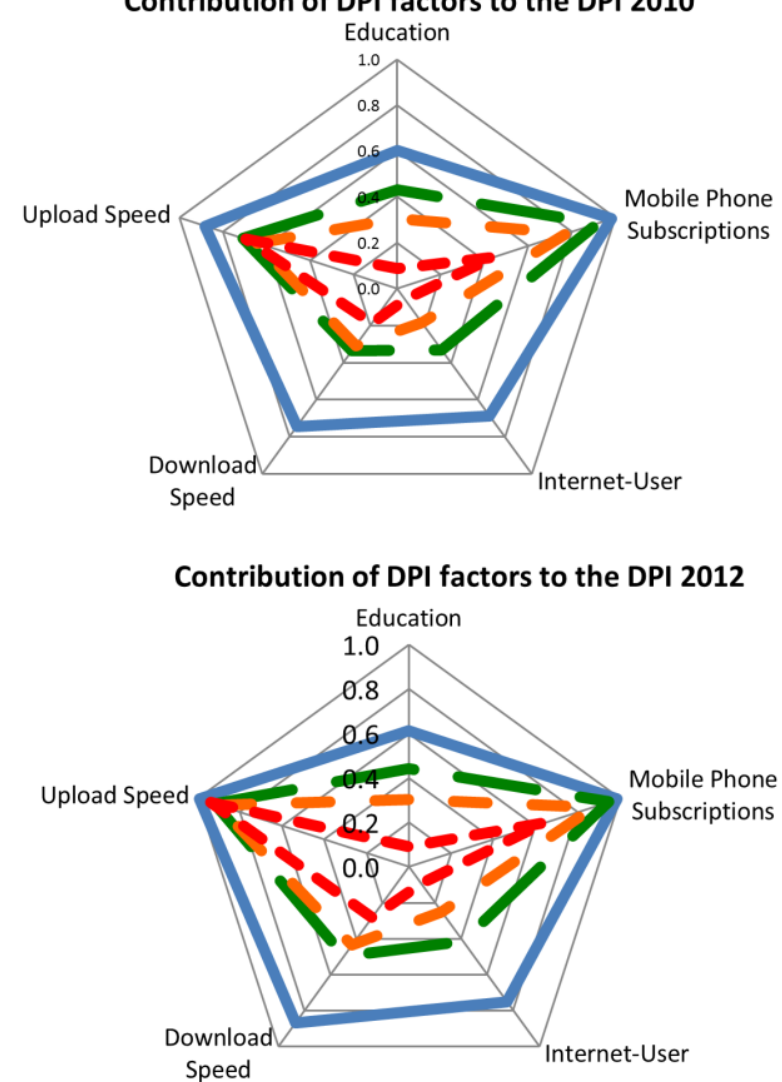

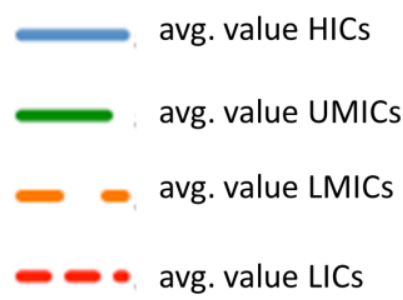

Figure 7: Spider plots showing the contribution to the DPI for each factor and year.

The pursuit of sustainability assumes that we know what can be sustained and have the capacity to maintain an equilibrium. In contrast, there is the concept of resilience, which acknowledges disequilibrium and nonlinear change. With 'resilience', dynamics and complexities are acknowledged, certainty is not required, and the emphasis is on adaptive capacity and management, rather than stationary (Benson \& Craig, 2014). Dynamics and complexity is what we observe with the DPI analysis. Within the 5-year time frame of this study, we have been unable to determine a 'perfect' DPI score for any of the countries 
examined.

The decrease of the global average DPI in each of the analysed years is a good sign. However, the gap between the DPI scores of the different income classes is currently widening, rather than closing: the data-rich are getting richer and the data-poor are getting relatively poorer. In particular, many African countries need investment in ICT to improve their capabilities in disaster management (from preparedness mapping, to early warning and post-disaster response), as well as for addressing issues arising from climate change and rapid population growth.

The thresholds set here to calculate the DPI are not absolute and are likely to require an update in future. With an ever-increasing amount of data there is also the requirement to move more data. For instance, there is now a large amount of freely available, internetdownloadable satellite remote sensing data, such as from NASA's Landsat or ESA's Sentinel sensors, that can be used for DRR applications (Krishnamoorthi, 2016, Kotovirta et al., 2015, Schlaffer et al., 2015, Teeuw et al., 2012). However, it is worth noting that when switching from using Landsat-7 to Landsat-8 remote sensing data (e.g. for regional land cover monitoring), the size of a typical Landsat scene increased by $40-50 \%$ - from about $680 \mathrm{Mb}$ to $1 \mathrm{~Gb}$. Fast Internet connections are required to download and use such large-volume data: countries with a high Data Poverty score face more challenges to access such data. The DPI provides a means of monitoring such capabilities.

\section{Data Poverty, Sustainable Development and Disaster Risk Reduction}

The world has experienced an increasing number and impact of disasters in the past decades.

Many regions, each with distinctive characteristics, are exposed to natural hazards. The main causes for this increase can be attributed to a higher frequency of extreme hydrometeorological events, most likely related to climate change, and to an increase in the exposure of vulnerable population (IPCC, 2007, van Westen, 2013).

The ICT development of a country is clearly linked with its potential economic 
development (ITU, 2012) and the DPI is suitable for monitoring national-scale ICT and

higher education developments on an annual timescale. For disaster risk reduction and climate change adaptation, the DPI can be utilised as a vulnerability monitoring tool (Craig, 2010). Reporting the required data at district level, rather than as a national average, would enhance the DPI analysis, for instance enabling monitoring of urban versus rural information access.

Improved monitoring using the DPI requires more freely available data from all countries and faster reporting of that data. However, as of mid-June 2015, apart from the Internet speed data (which are free data from a commercial company), no updated data for 2014 was available online at the World Bank website or the UN statistics website When international aid for ICT development is provided, the DPI could serve as a useful tool for monitoring progress: the data required to calculate the DPI should be a minimum requirement for monitoring associated with international development funding.

The world faces a future in which we humans are unsure of what we can sustain (Milly et al., 2007). The resilience concept is a promising way of addressing the challenges ahead, incorporating the dynamic and nonlinear change observed with the DPI (Benson \& Craig, 2014). Whether we strive for Sustainable Development Goals or aim to increase the resilience of communities and countries, the DPI is a suitable tool for monitoring development, in conjunction with other methods of global risk analysis, such as the World Risk Index (Alliance Development Works, 2013) and the Global Assessment Reports of the United Nations (2015).

\section{Acknowledgements}

The authors thank the Leverhulme Trust for funding to support a preliminary part of this research.

\section{References}

1. Norris P. (2001) Digital Divide - Civic Engagement, Information Poverty, and the Internet 
Worldwide (http://ksghome.harvard.edu/ pnorris/Books/Digital Divide.htm), Cambridge University Press.

2. Desiere S., Vellema W., \& D'Haese M. (2015) A validity assessment of the Progress out of Poverty Index (PPI) ${ }^{\mathrm{TM}}$. Evaluation and Program Planning, 49(0):10-18.

3. The Economist (Nov 15 ${ }^{\text {th }}$ 2014) Data and development: Off the map - Rich countries are deluged with data; developing ones are suffering from drought. The Economist (online: http://www.economist.com/news/international/21632520-rich-countries-are-deluged-datadeveloping-ones-are-suffering-drought).

4. Griggs D., et al. (2013) Policy: Sustainable development goals for people and planet. Nature 495(7441):305-307.

5. Kelman I., Gaillard J.C., \& Mercer J. (2015) Climate Change's Role in Disaster Risk Reduction's Future: Beyond Vulnerability and Resilience. Int J Disaster Risk Science, 6(1): 21-27.

6. Benson M.H. \& Craig R.K. (2014) The end of sustainability. Society \& Natural Resources, 27(7):777-782.

7. The European Evaluation Network for Rural Development (2014) Defining proxy indicators for rural development programmes (working document), $21 \mathrm{pp}$.

8. Buys P., Dasgupta S., Thomas T.S., \& Wheeler D. (2009) Determinants of a Digital Divide in Sub-Saharan Africa: A Spatial Econometric Analysis of Cell Phone Coverage. World Development, 37(9):1494-1505.

9. Houston J.B., et al. (2015) Social media and disasters: a functional framework for social media use in disaster planning, response, and research. Disasters, 39(1):1-22.

10. National Telecommunications and Information Administration (1995) Falling through the net: A survey of the 'Have Nots' in rural and urban America (U.S. Department of Commerce).

11. World Bank (2006) Information and communications for development 2006. In: Global trends and policies, The World Bank, Washington DC, U.S.A.

12. International Telecommunication Union (2012) International Telecommunication Union Measuring the Information Society 2012. (Place des Nations, Geneva, Switzerland), 213 pp.

13. Van Dijk J.A.G.M. (2006) Digital divide research, achievements and shortcomings. Poetics, 34(4):221-235.

14. Huang C.Y. \& Chen H.N. (2010) Global digital divide: A dynamic analysis based on the bass model. Journal of Public Policy \& Marketing, 29(2):248-264.

15. Hilbert M. (2011) The end justifies the definition: the manifold outlooks on the digital divide and their practical usefulness for policy-making. Telecommunications Policy, 35(8):715-736. 
16. Baban S.M., Ramlal B., \& Al-Tahir R. (2004) Issues in information poverty and decisionmaking in the Caribbean region, a way forward. West Indian Journal of Engineering, 27(1):28-37.

17. Baban S.M., Thomas D., Canisius F., \& Sant K.J. (2008) Managing development in the hillsides of Trinidad and Tobago using geoinformatics. Sustainable development 16(5):314328.

18. Leidig M. \& Teeuw R.M. (2015a) Quantifying and Mapping Global Data Poverty. PLOSONE PLoS ONE 10(12): e0145591. doi: 10.1371/journal.pone.0145591.

19. World Bank data-website (2014), online: http://data.worldbank.org.

20. United Nations data-website (2014), online: http://data.un.org.

21. Goodchild M.F. \& Glennon J.A. (2010) Crowdsourcing geographic information for disaster response: a research frontier. Int. J. Digital Earth, 3(3):231-241.

22. Yin J., Lampert A., Cameron M., Robinson B., \& Power R. (2012) Using social media to enhance emergency situation awareness. IEEE Intelligent Systems, 27(6):52-59.

23. Yates D. \& Paquette S. (2011) Emergency knowledge management and social media technologies: A case study of the 2010 Haitian earthquake. International Journal of Information Management, 31(1):6-13.

24. The World Bank. (2014). World Development Report 2014 Risk and Opportunity - Managing Risk for Development, 362 pp.

25. Alliance Development Works (2013) World Risk Report 2013, 73 pp.

26. World Higher Education Database (2014), retrieved 10.10.2014, from http://www.whed.net/home.php.

27. 4icu.org (2014), retrieved 10.10.2014, from http://www.4icu.org.

28. Ford D.M. (2007) Technologizing Africa: On the bumpy information highway. Computers and Composition, 24(3):302-316.

29. Fuchs C. \& Horak E. (2008) Africa and the digital divide. Telematics and Informatics, 25(2):99-116.

30. Inrin News (2015) DISASTERS: Asia's 2012 figures and trends. (online: http://www.irinnews.org/report/97021/disasters-asia-s-2012-figures-and-trends).

31. PriMetrica Inc. (2014) Tele Geography - Submarine Cable Map. p The Submarine Cable Map is a free resource from TeleGeography. Data contained in this map is drawn from the Global Bandwidth Research Service and is updated on a regular basis (online: http://www.submarinecablemap.com/).

32. Compaine B.M. (2001) The digital divide: Facing a crisis or creating a myth? (MIT Press). 
33. Dutton W.H., Gillett S.E., McKnight L.W., \& Peltu M. (2004) Bridging broadband Internet divides: reconfiguring access to enhance communicative power. Journal of Information Technology, 19(1):28-38.

34. Chinn M.D. \& Fairlie R.W. (2004) The Determinants of the global digital divide: A crosscountry analysis of computer and Internet penetration. Economic Growth Center, Yale University (Retrieved from: http://www.econ.yale.edu/growth_pdf/cdp881.pdf).

35. James J. (2011) Sharing mobile phones in developing countries: Implications for the digital divide. Technological Forecasting and Social Change, 78(4):729-735.

36. Kim M.C. \& Kim J-K. (2001) Digital divide: Conceptual discussions and prospect. The Human Society and the Internet Internet-Related Socio-Economic Issues, (Springer), 78-91.

37. United Nations University (2014) World Risk Report 2014. (Institute for Environment and Human Security), 74 pp.

38. Lu M.T. (2001) Digital divide in developing countries. Journal of Global Information Technology Management, 4(3):1-4.

39. Wesolowski A., et al. (2014) Commentary: Containing the Ebola Outbreak - the Potential and Challenge of Mobile Network Data. PLOS Currents Outbreaks. 2014 Sep 29 . Edition 1. doi: 10.1371/currents.outbreaks.0177e7fcf52217b8b634376e2f3efc5e..

40. Davidson O..G (2014) Can We Get Ahead of Ebola? (Earthzine, online: http://earthzine.org/2014/10/07/can-we-get-ahead-of-ebola/).

41. Pakhare A.P., Bali S., \& Kalra G. (2013) Use of mobile phones as research instrument for data collection. $201325(2): 95$ - 98.

42. Lüge T. \& MSF-CH GIS Unit (CartONG) (2014) GIS Support for the MSF Ebola response in Guinea in 2014. (Médecins Sans Frontières - Operational Center Geneva), 46 pp.

43. Leidig M. \& Teeuw R.M. (2015b) Free software: a review, in the context of disaster management. International Journal of Applied Earth Observation and Geoinformation, 42(0):49-56.

44. Teeuw R.M., Leidig M., Saunders C., \& Morris N. (2012) Free or low-cost geoinformatics for disaster management: Uses and availability issues. Environmental Hazards, 12(2):112-131.

45. Danzeglocke J., 2015, online: http://www.un-spider.org/sites/default/files/ EO2015_Danzeglocke.pdf, 2015, last accessed 25.09.2015.

46. Krishnamoorthi, N. (2016). Role of Remote Sensing and GIS in Natural-Disaster Management Cycle. Imperial Journal of Interdisciplinary Research, 2(3), 144-154.

47. Kotovirta, V., Toivanen, T., Tergujeff, R., Häme, T., \& Molinier, M. (2015). Citizen Science for Earth Observation: Applications in Environmental Monitoring and Disaster Response. 
ISPRS - International Archives of the Photogrammetry, Remote Sensing and Spatial Information Sciences, XL-7/W3, 1221-1226. doi: 10.5194/isprsarchives-XL-7-W3-1221-2015.

48. Schlaffer, S., Matgen, P., Hollaus, M., \& Wagner, W. (2015). Flood detection from multi-temporal SAR data using harmonic analysis and change detection. International Journal of Applied Earth Observation and Geoinformation, 38, 15-24.

49. IPCC (2007) Climate Change 2007: impacts, adaptation and vulnerability: contribution of Working Group II to the fourth assessment report of the Intergovernmental Panel on Climate Change (Cambridge University Press).

50. Van Westen C.J. (2013) Remote sensing and GIS for natural hazards assessment and disaster risk management. In: Shroder, J. \& Bishop, MP (eds.), Treatise on Geomorphology (Academic Press, San Diego) 3:259-298.

51. Craig R.K. (2010) 'Stationarity is Dead'-Long Live Transformation: Five Principles for Climate Change Adaptation Law. Harvard Environmental Law Review, 34(1):9-75.

52. Milly P., et al. (2007) Stationarity is dead. Ground Water News \& Views, 4(1):6-8.

53. United Nations (2015) GAR - Global Assessment Report on Disaster Risk Reduction. (UNISDR, online: http://www.preventionweb.net/english/hyogo/gar/2015/en/ gar-pdf/GAR2015_EN.pdf), 316 pp. 
Click here to download high resolution image

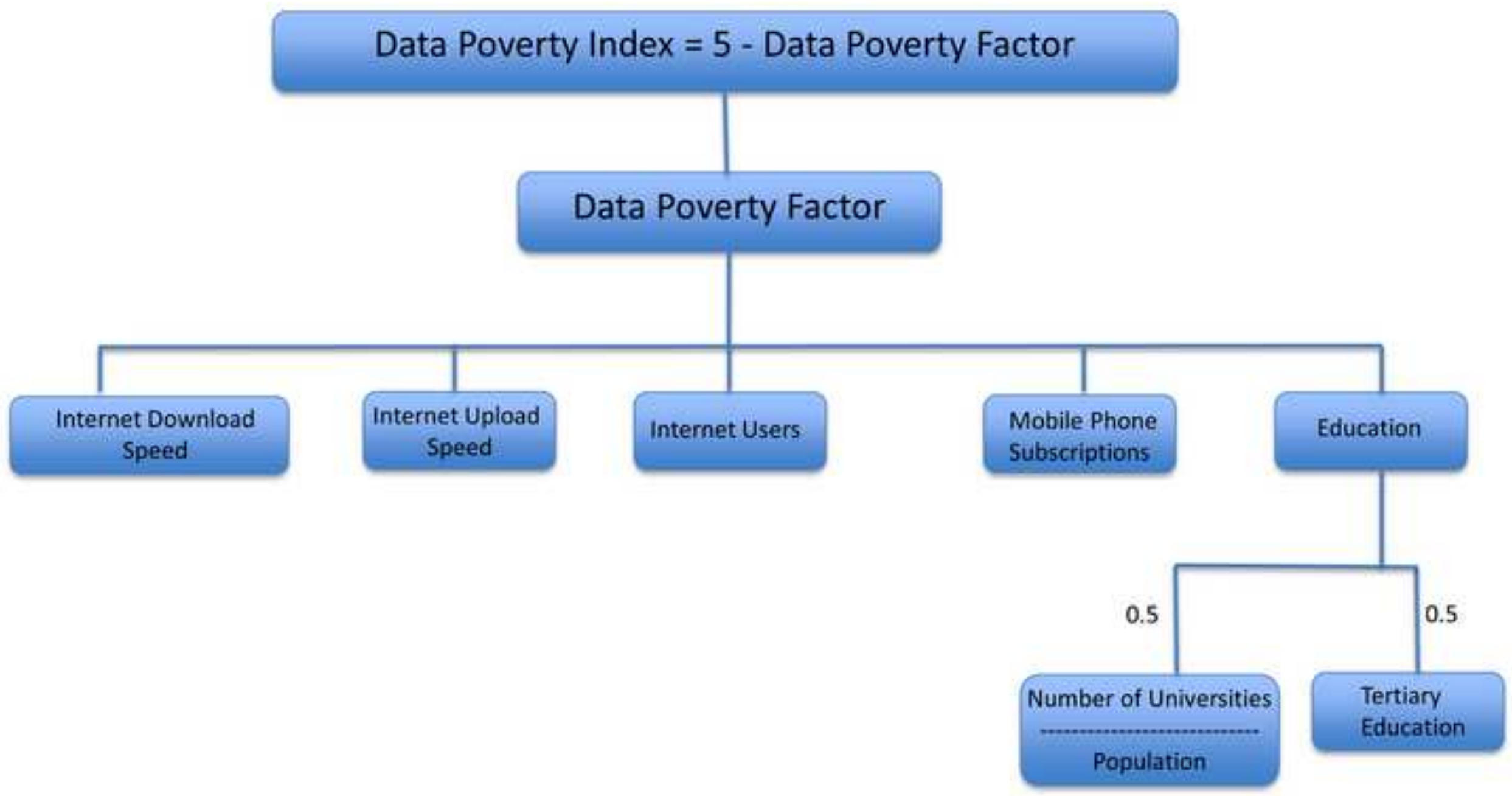




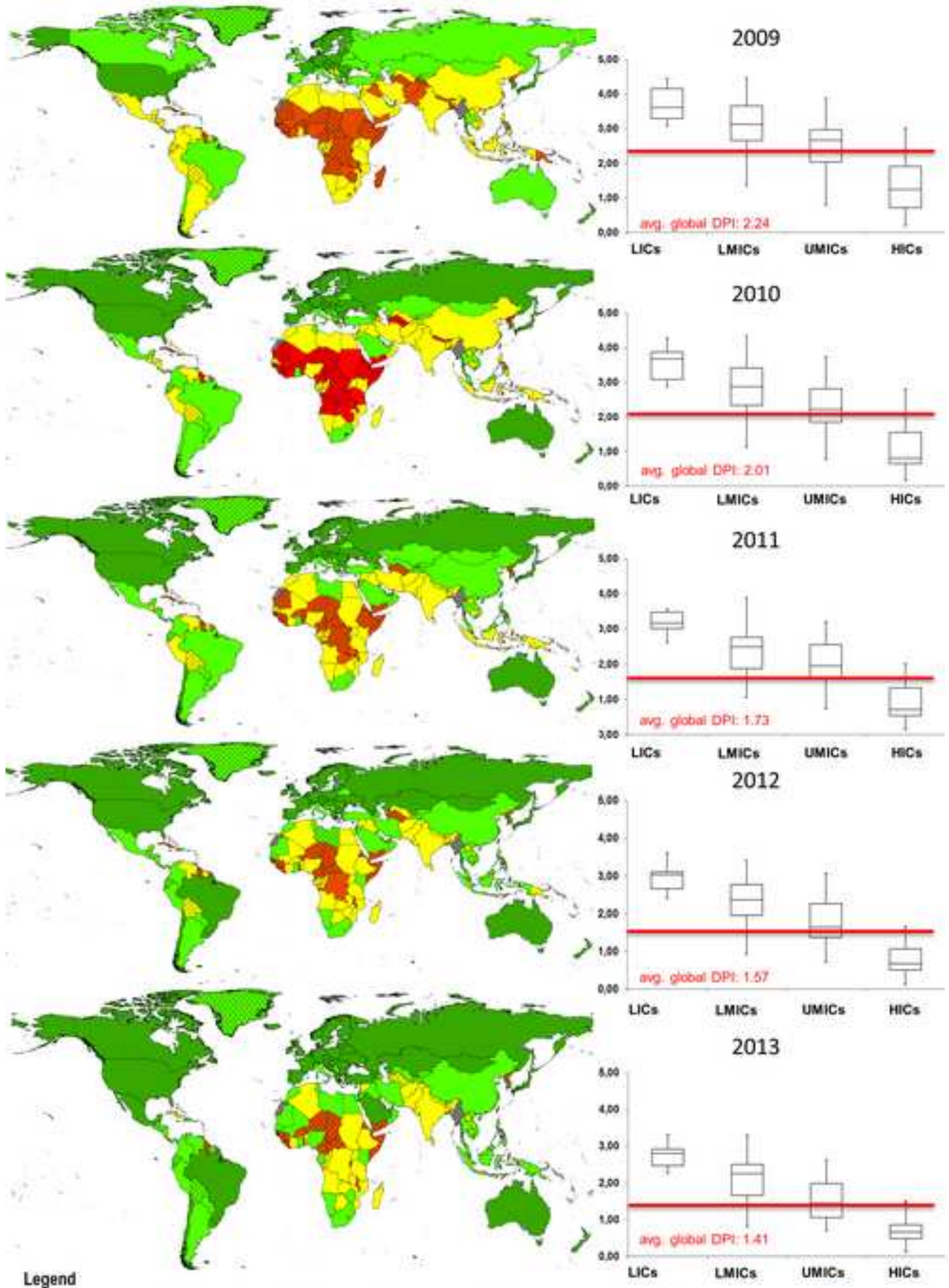

Legend

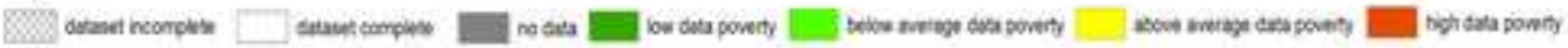




\section{Data Poverty Index Development 2009-2013}

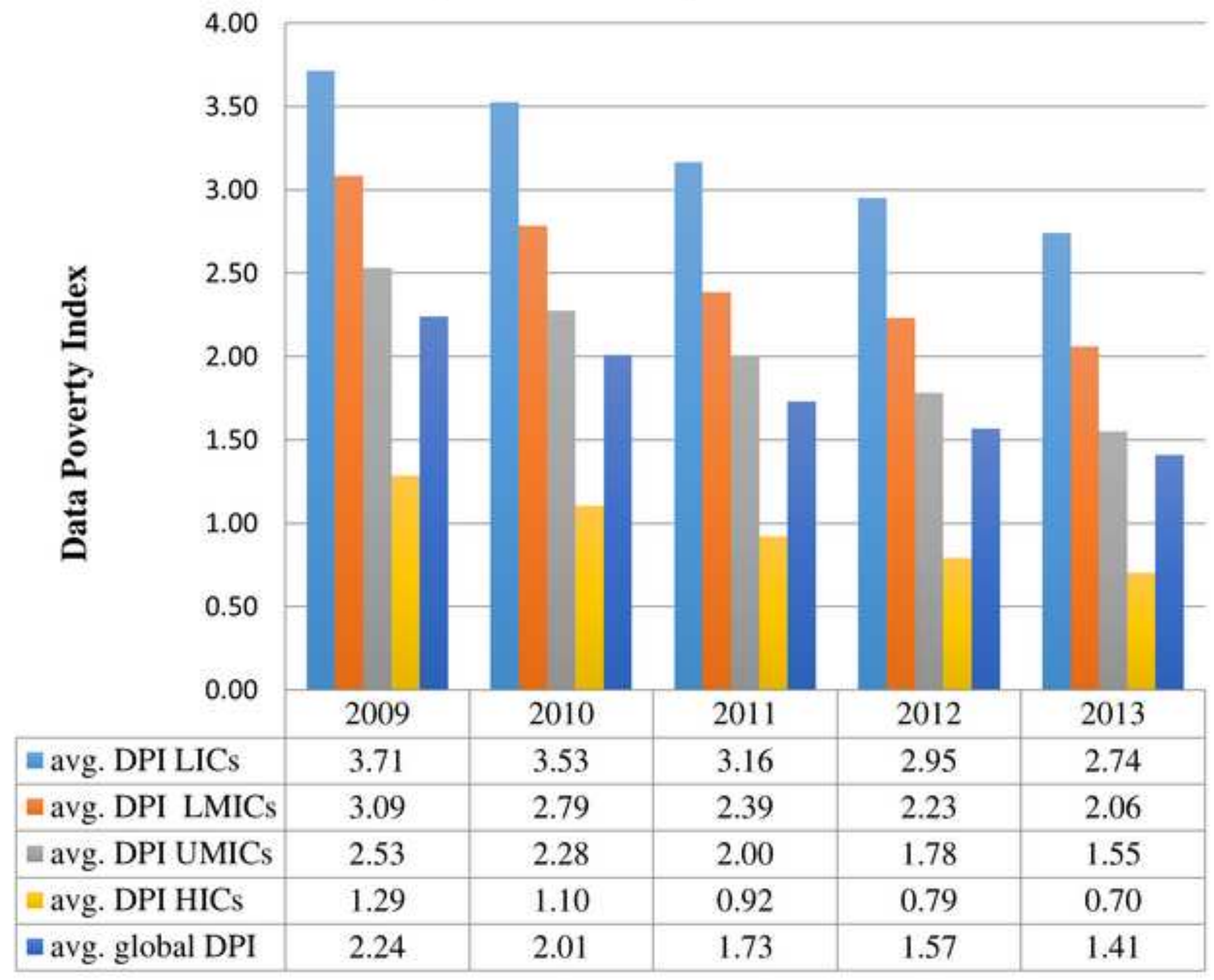


Normalisation of DPI time series Analysis Average difference of the DPI to the average $\mathrm{DPI}_{G}$

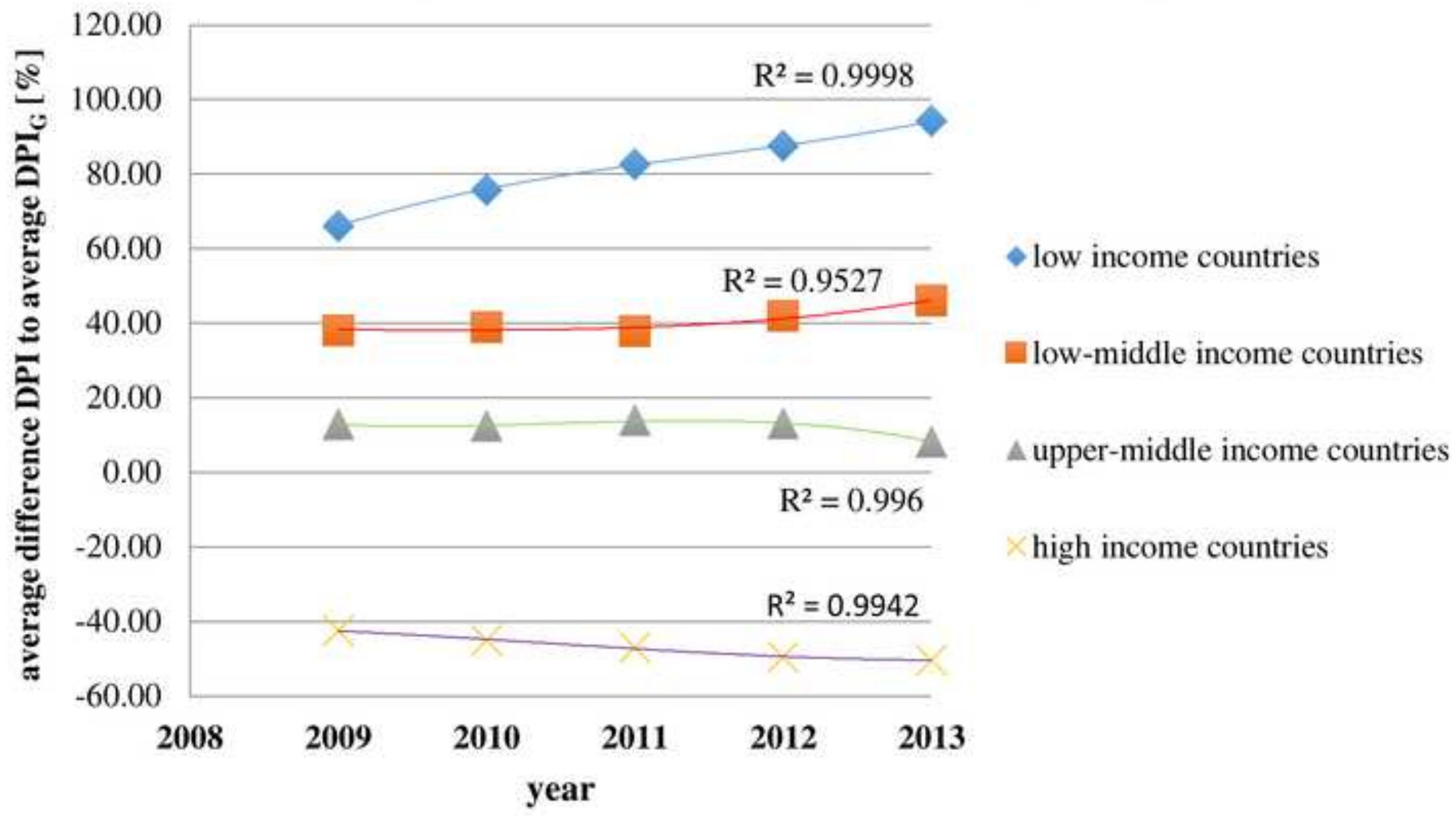


Normalization of DPI time series analysis Average difference of the DPI to the average average $\mathrm{DPI}_{G}$

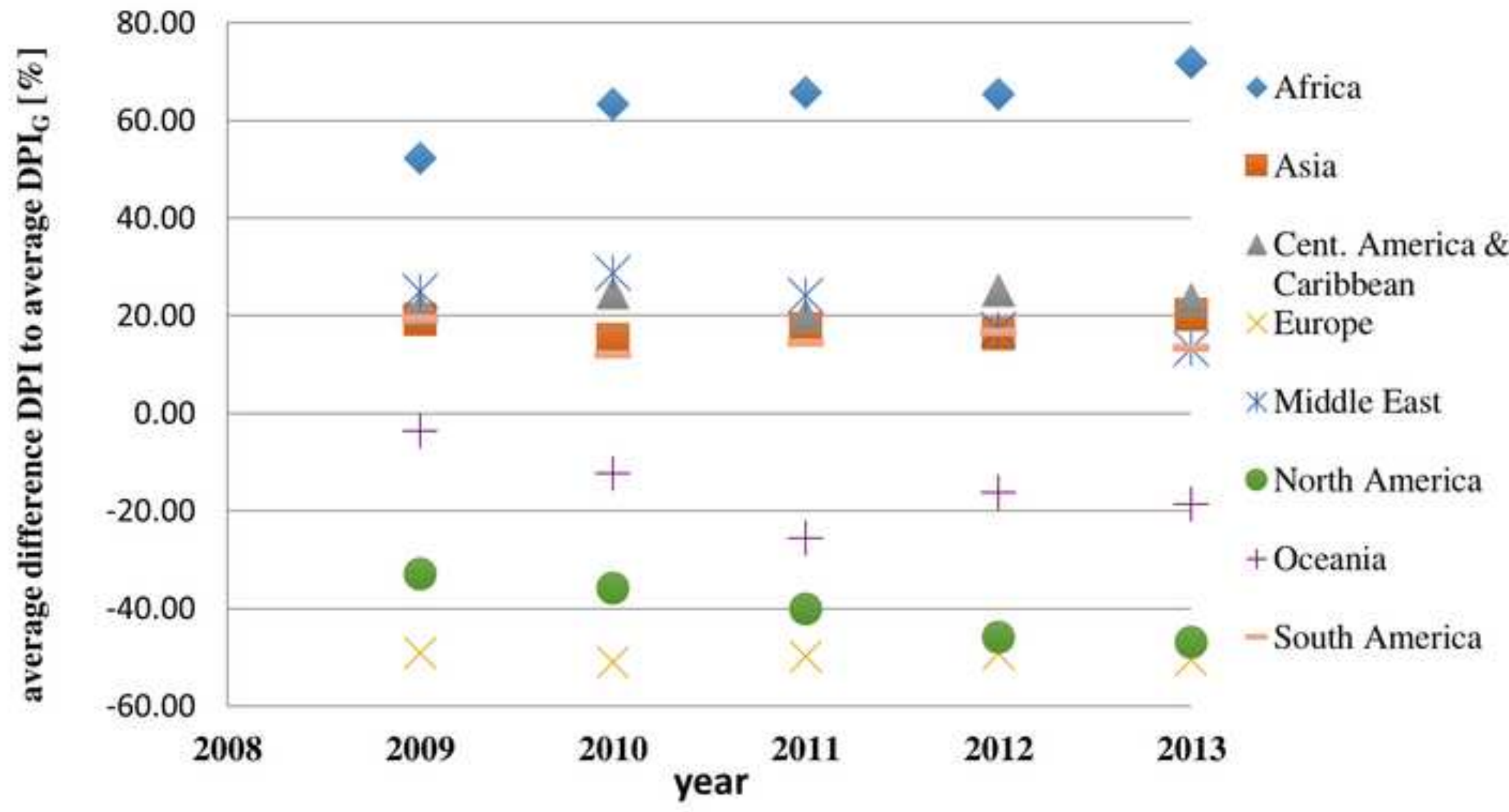




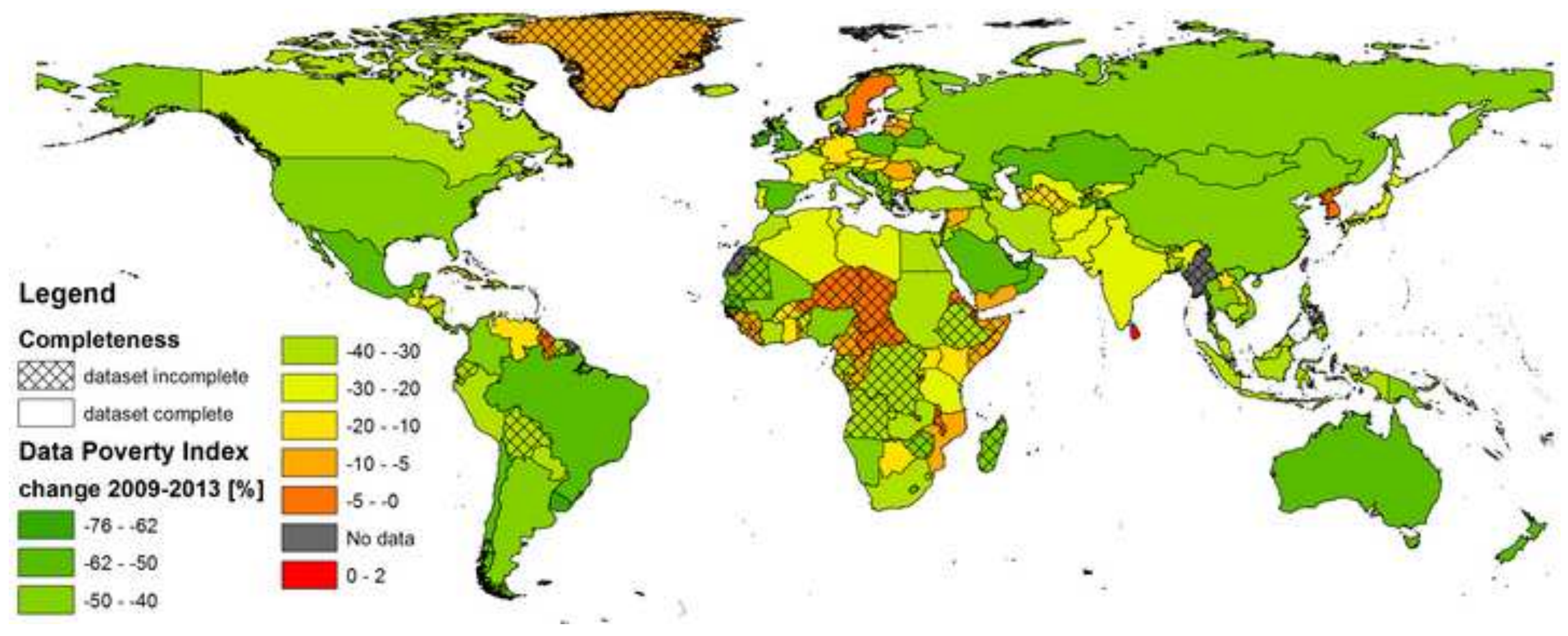




\section{Figure 7}

Click here to download high resolution image
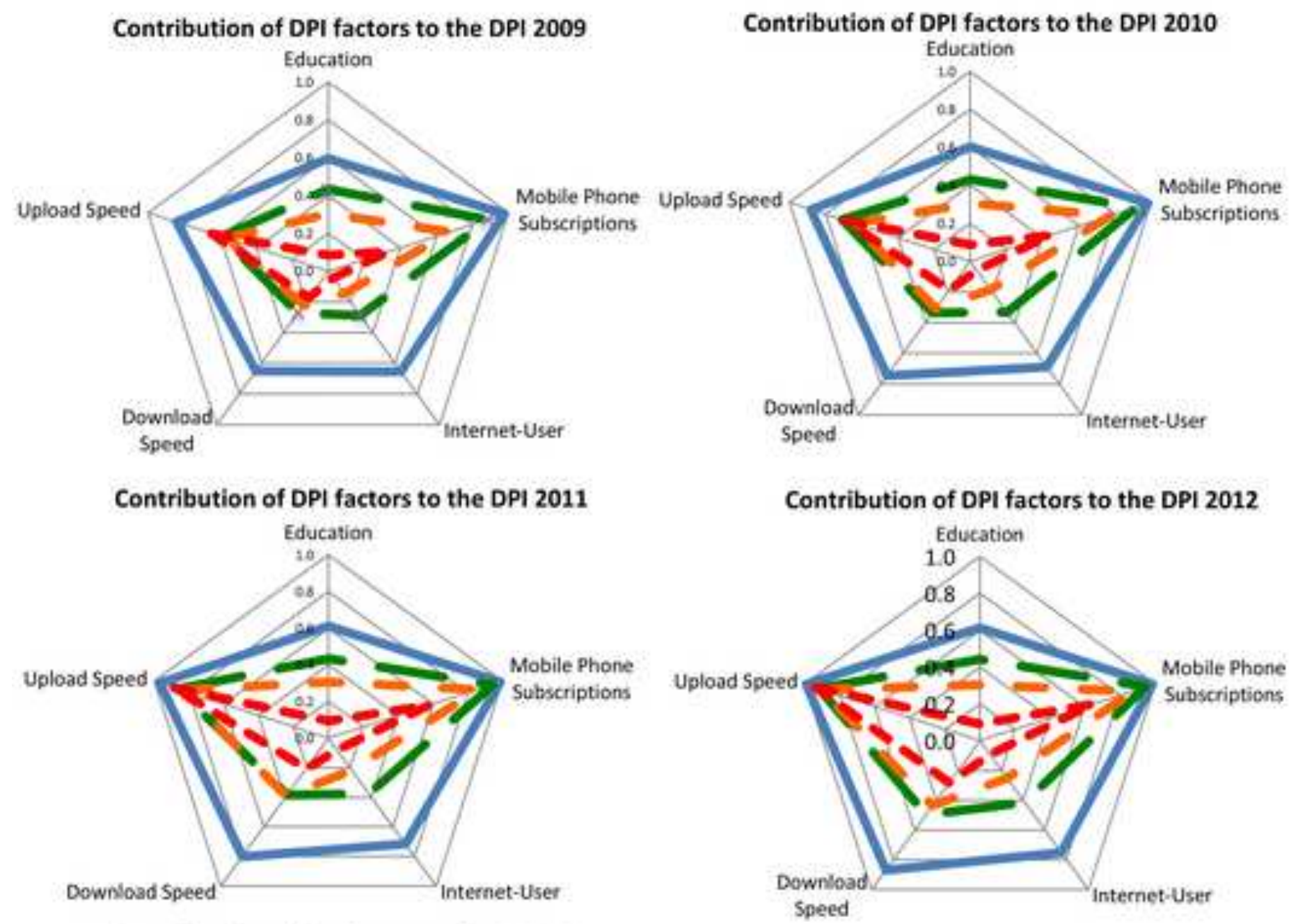

\section{Contribution of DPI factors to the DPI 2013}
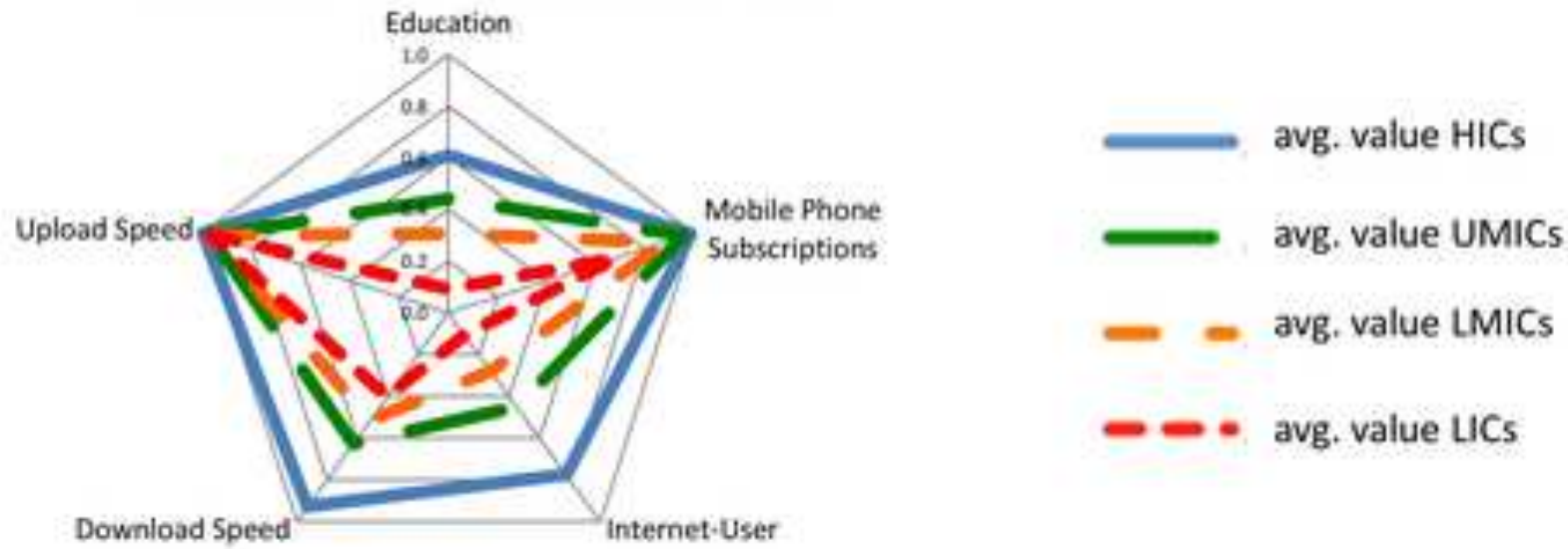

Download Speed Internet-User 


Country
Åland Islands
Anguilla
Bonaire, Sint Eustatius and
Saba

British Virgin Islands

Cook Islands

Falkland Islands (Malvinas)

French Guiana

Gibraltar

Guadeloupe

Guernsey

Holy See

Jersey

Martinique

Mayotte

Montserrat

Nauru

Niue

Norfolk Island

Pitcairn

Réunion

Saint Helena

Saint Pierre and Miquelon

Saint-Barthélemy

Sark

Svalbard and Jan Mayen

Islands

Tokelau

Wallis and Futuna Islands

Western Sahara

Channel Islands

Samoa

Afghanistan

Albania

Algeria

American Samoa

Andorra

Angola

Antigua and Barbuda

Argentina

\section{Continent}

Europe

Latin America and the

Caribbean

Latin America and the

Caribbean

Latin America and the

Caribbean

Oceania

South America

South America

Europe

Latin America and the

Caribbean

Europe

Europe

Europe

Latin America and the

Caribbean

Africa

Latin America and the

Caribbean

Oceania

Oceania

Oceania

Oceania

Africa

Africa

Northern America

Latin America and the

Caribbean

Europe

Europe

Oceania

Oceania

Africa

Europe

Oceania

Asia

Europe

Africa

Oceania

Europe

Africa

Latin America and the

Caribbean

South America
Source In World Bank complete DPI

http://unstats 0

$\begin{array}{lll}\text { http://unstats } & 0 & 0\end{array}$

http://unstats $\quad 0 \quad 0$

http://unstats $\quad 0 \quad 0$

http://unstats $\quad 0 \quad 0$

http://unstats $\quad 0 \quad 0$

http://unstats $\quad 0 \quad 0$

http://unstats $\quad 0 \quad 0$

http://unstats $\quad 0 \quad 0$

http://unstats $\quad 0 \quad 0$

http://unstats $\quad 0 \quad 0$

http://unstats $\quad 0 \quad 0$

http://unstats $\quad 0 \quad 0$

http://unstats $\quad 0 \quad 0$

http://unstats $\quad 0 \quad 0$

http://unstats $\quad 0 \quad 0$

http://unstats $\quad 0 \quad 0$

http://unstats $\quad 0 \quad 0$

http://unstats $\quad 0 \quad 0$

http://unstats $\quad 0 \quad 0$

http://unstats $\quad 0 \quad 0$

http://unstats $\quad 0 \quad 0$

http://unstats $\quad 0 \quad 0$

http://unstats $\quad 0 \quad 0$

http://unstats $\quad 0 \quad 0$

http://unstats $\quad 0 \quad 0$

http://unstats $\quad 0 \quad 0$

http://unstats $\quad 0 \quad 0$

http://unstats $\quad 1 \quad 0$

http://unstats $\quad 1 \quad 0$

http://unstats $\quad 1 \quad 1$

http://unstats $\quad 1 \quad 1$

http://unstats $\quad 1 \quad 1$

http://unstats $\quad 1 \quad 0$

http://unstats $\quad 1 \quad 1$

http://unstats $\quad 1 \quad 0$

http://unstats $\quad 1 \quad 1$

http://unstats $\quad 1 \quad 1$ 